\title{
Toward Understanding the Role of Aphid Effectors in Plant Infestation
}

\author{
Patricia A. Rodriguez and Jorunn I. B. Bos \\ Cell and Molecular Sciences, The James Hutton Institute, Dundee, DD2 5DA U.K.
}

Submitted 18 May 2012. Accepted 17 August 2012.

\begin{abstract}
In recent years, immense progress has been made toward understanding the functions of effectors from a range of plant pathogens, such as oomycetes, fungi, bacteria, and nematodes. Like plant pathogens, aphids form close associations with host plants, featuring signal exchange between the two organisms. While feeding and probing, aphids deliver effector proteins mixed with saliva directly into the host-stylet interface. With the increasing availability of aphid genome and transcriptome sequence data, aphid effector biology is emerging as a new and exciting area of research. In this review, we provide an overview of recent advances in the aphid effector biology field and highlight some of the current questions.
\end{abstract}

Plant pathogens and pests generally need to form close associations with their hosts to enable survival and reproduction. One important step in establishing such associations is the delivery of effectors inside host plants to modulate host cell processes and enable colonization. Over the past years, significant progress has been made to identify effectors from a range of plant pathogens, including oomycetes, fungi, bacteria, and nematodes (Bozkurt et al. 2012; Deslandes and Rivas 2012; Hewezi and Baum 2013; Rafiqi et al. 2012). The increasing availability of genome and transcriptome sequence data from various plant pathogens has allowed the development of bioinformatics approaches to predict effector repertoires (Bellafiore et al. 2008; Bos et al. 2010; Guttman et al. 2002; Haas et al. 2009; Joly et al. 2010). These effector identification approaches have led to extensive functional characterization studies, which provided novel insights into the role of some effectors in targeting specific host proteins and modifying their activity. Although the use of the term "effector" has been much debated, within the context of this review, we consider effectors to be proteins or small molecules secreted by plant-associated organisms that alter host cell structure and function.

Aphids are insects with specialized mouth parts that mainly feed on the plant phloem (Fig. 1). These insects induce extensive feeding damage, achieve high population densities, and transmit economically important viruses to many crops worldwide. Among the over 5,000 aphid species, some have broad host ranges and cause damage to a wide range of crops, whereas others are restricted to only a few plant species (Blackman and Eastop 2000). Genomics resources recently became available

Corresponding author: J. I. B. Bos; E-mail: jorunn.bos@hutton.ac.uk; Telephone: +004401382568 700 .

(C) 2013 The American Phytopathological Society for various aphid species (International Aphid Genomics Consortium 2010; Ramsey et al. 2007). These resources, in combination with the availability of host plant genome sequences, provide an excellent opportunity to study the molecular events taking place during economically important plant-aphid interactions.

In plant-pathogen interactions, there is a significant amount of knowledge of the plant cellular changes taking place to mount defense responses or promote disease. Recent evidence suggests that aphids, like plant pathogens, deliver effector proteins inside their hosts to modulate host cell processes (Hogenhout and Bos 2011). These aphid effectors are expressed in the aphid salivary glands and, thus, thought to be secreted into saliva for subsequent delivery into the host plant. Considering the presence of large and diverse sets of secreted salivary proteins in all aphids studied, it is likely that salivary proteins with effector activities are important players in plant-aphid interactions. Critically, these observations point to conceptual parallels between the interactions of distinct parasites with their hosts. In this review, we will discuss the exciting progress that has been made in recent aphid effector protein identification efforts. We will then describe efforts toward understanding the role of aphid effector proteins in host cell modulation and infestation. These recent developments have led to novel questions about the molecular basis of plant-aphid interactions, which we will highlight here.

\section{The plant-aphid interface.}

Most aphid species predominantly feed from the phloem and, thus, their survival is dependent on their ability to maintain contact with the phloem for extended periods of time. To reach the phloem, aphids have specialized mouth parts, or stylets, that navigate through the different plant cell layers. It is thought that both $\mathrm{pH}$ and carbohydrate content are cues for aphids to find their way to the phloem (Hewer et al. 2011). While searching for vascular bundles, the stylets follow a mainly extracellular pathway (Tjallingii and Esch 1993). However, the stylets briefly probe most cells along this pathway and, thus, are also in direct contact with the cytoplasm of the plant cells. While feeding and probing, aphids secrete saliva directly into the host-stylet interface (Fig. 1). Initially, aphids secrete sheath saliva, which is hypothesized to form a protective layer around the stylets (Tjallingii 2006). During both probing and feeding, the aphids secrete watery saliva, which is thought to be involved in modulation of host cell processes. Therefore, aphid stylets form an interface with the host plant where signals are exchanged. An important observation is that aphids also spend a considerable time on nonhost species, where they probe the leaf tissue and secrete saliva but, for un- 
known reasons, are unable to ingest phloem sap (McLean and Kinsey 1968; Wiktelius 1982). These findings suggest that aphids, like plant pathogens, interact with nonhost plants at the molecular level but potentially are not successful in suppressing plant defenses or releasing nutrients.

In a groundbreaking study, evidence for a role of aphid saliva in plant defense suppression was first provided by Will and associates $(2007,2009)$, who showed that aphid saliva collections can suppress sieve element occlusion. Sieve element occlusion is a common mechanism in plants to prevent loss of phloem sap upon injury and generally involves a $\mathrm{Ca}^{2+}$ influx into sieve elements (Knoblauch et al. 2001). The suppression of this plant response by aphids is thought to involve the secretion of calcium-binding proteins within saliva into the sieve elements, allowing aphids to feed freely on the phloem (Will et al. 2007). It is likely that, in addition to calcium-binding proteins, other salivary proteins are involved in suppression of host defenses, including sieve element occlusion.

\section{The emerging aphid effector paradigm.}

In addition to suppressing plant defense responses, aphids appear to modulate a range of host cell processes. For example, some aphid species, such as the rosy apple aphid, cause deformation of fruit and leaves upon feeding, whereas other aphid species can trigger the formation of a variety of gall types (van Emden and Harrington 2007). Another interesting observation that is relevant to promoting infestation is that aphids can change the allocation of nutrients in host plants by increasing nutrient flow to infested tissues (Girousse et al. 2005). In addition, a recent study by Wilson and associates (2011) showed that aphids manipulate host nitrogen metabolism by increasing the levels of nitrogen reductase activity. It was speculated that aphid saliva components could be responsible for this observation. However, the molecular mechanisms underlying the modulation of various host processes remain still to be investigated.

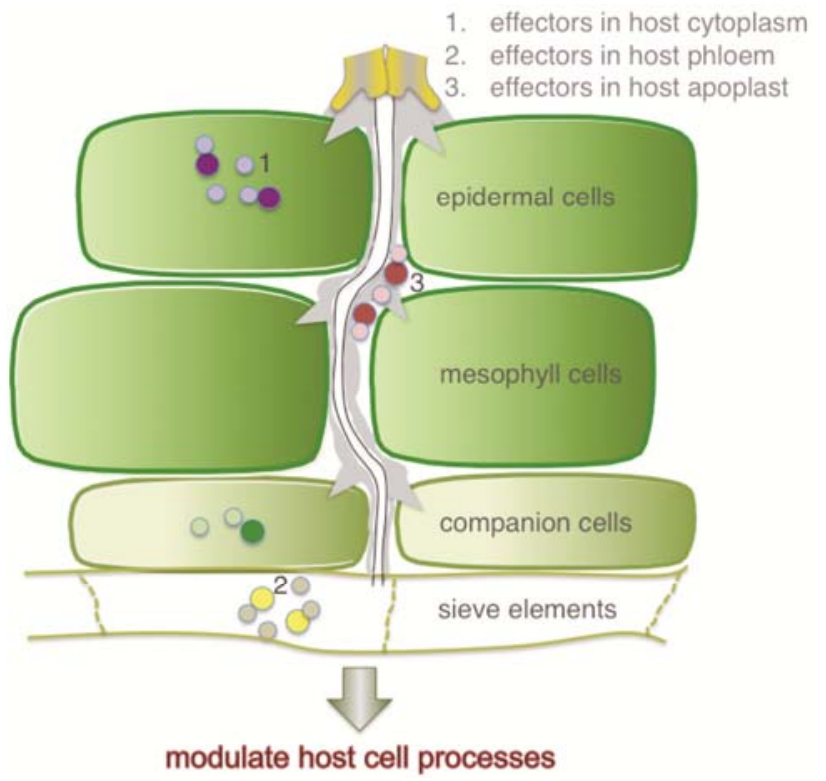

Fig. 1. Model for delivery of aphid effectors inside different plant cell types and compartments. Aphid mouth parts (or stylets) penetrate the leaf surface and follow a mainly intercellular pathway to reach the phloem. Most cells along this pathway are punctured by the aphid stylets. Saliva is secreted along the intercellular stylet pathway, into the different cell types along the stylet pathway and into the phloem. This saliva contains proteins that are predicted to function as effectors through interacting with or modifying host proteins or both. These events likely result in suppression of host defenses and a change of host physiology to promote nutrient uptake.
In contrast to the plant-pathogen interaction field, there is relatively little knowledge about the plant (extra)cellular changes taking place to mount defense responses or promote susceptibility in plant-aphid interactions. In a first layer of defense against plant pathogens, plants can recognize microbe associated molecular patterns (MAMPs) to mount pattern-triggered immunity (PTI) (Jones and Dangl 2006). Successful plant pathogens, however, deliver effectors inside their hosts to suppress this and other types of plant defenses by targeting important plant defense-signaling components. Nevertheless, plant pathogen effectors that are deployed to suppress host defenses are recognized by plant disease resistance $(\mathrm{R})$ proteins, in particular, host genotypes, resulting in effector-triggered immunity (ETI) (Jones and Dangl 2006)

Recognition of several aphid species has been shown to involve disease $\mathrm{R}$ proteins similar to those that recognize plant pathogens, cytoplasmic proteins containing a nucleotide binding (NB) site domain and leucine-rich repeat (LRR) regions. The tomato $M i-1$ gene was the first cloned NB-LRR gene that confers resistance to aphids; more specifically, to the aphid species Macrosiphum euphorbiae (potato aphid) (Rossi et al. 1998). Interestingly, this $R$ gene confers resistance not only to aphids but also to nematodes, whiteflies, and psyllids (Casteel et al. 2006; Milligan et al. 1998; Nombela et al. 2003). In addition, the NB-LRR gene Vat confers resistance to Aphis gossypii (melon-cotton aphid) in melon (Dogimont et al. 2010). Other resistances identified in, for example, barley, wheat, lettuce, soybean, and Medicago truncatula, are potentially conferred by NB-LRR genes because they map to genomic regions with NB-LRR sequences (Dogimont et al. 2010; Kim et al. 2010; Klinger et al. 2005; Klinger et al. 2009; Seah et al. 1998; Wroblewski et al. 2007). The involvement of NB-LRR proteins in plant resistance to aphids indicates that aphids, like plant pathogens, secrete effectors inside their host that are recognized in incompatible interactions. Therefore, to understand the molecular mechanisms underlying plant resistance to aphids, it is essential to identify such effectors and investigate their activities. Furthermore, resistance conferred by $\mathrm{Mi}-1$ and Vat as well as other identified resistances are biotype specific, potentially reflecting effector repertoire variation within aphid species (Dogimont et al. 2010; Hill et al. 2010; Rossi et al. 1998). Indeed, and as further detailed below, the salivary proteomes of Diuraphis noxia (Russian wheat aphid) biotypes that differ in virulence on wheat genotypes with different resistances show variation in numbers as well as expression levels of candidate effectors proteins (Nicholson et al. 2012). This further supports the model that aphids, like plant pathogens, secrete effectors directly inside host cells that target cell processes and trigger immunity on select host genotypes.

To date, the role of perception of MAMP-like molecules from aphids in plant-aphid interactions remains elusive. Elicitor activity has been observed in saliva of the aphid species Myzus persicae (green-peach aphid) and is thought to involve a low molecular weight proteinaceous molecule (de Vos and Jander 2009). In addition, the Mp10 candidate effector from $M$. persicae suppressed the reactive oxygen species burst triggered by the bacterial MAMP flg22 but not fungal chitin, showing for the first time that salivary candidate effectors can suppress PTI (Bos et al. 2010). Future identification and characterization of potential MAMP-like molecules from aphids, their receptors, and suppressors of PTI promises to reveal novel insights into the basal defense mechanisms that plants employ to defend themselves against these insects.

With aphid saliva being secreted both extra- and intracellular into plant cells, the phloem, and the apoplast, we predict that effectors are delivered into different host cell compartments (Fig. 1.). Based on our current knowledge on the func- 
tions of plant pathogen effectors, it is likely that aphid effectors also interact with host proteins, or virulence targets, at these different sites to alter their mode of action to suppress defenses and benefit infestations. As a counter-defense mechanism, resistant plants may have evolved mechanisms to evade or recognize such modification of host targets by aphids, in line with the zig-zag-zig model proposed by Jones and Dangl (2006). The challenge now is to identify the key plant and aphid proteins involved in the different stages of this model to gain insight into the molecular basis of plant-aphid interactions.

\section{Identification of aphid salivary proteins.}

Aphid saliva has been the focus of research for many years. Initially, the emphasis was on understanding the role of aphid saliva in transmission of nonpersistent plant viruses and the physical and chemical properties of aphid saliva (Adams and Drew 1965; Adams and McAllan 1956; Miles 1959, 1965). More recently, it has become apparent that aphid saliva plays a crucial role in enabling infestation and the identification of salivary proteins with effector activities has become a hot topic. There are two different types of saliva, gelling and watery saliva, that differ in their protein composition (Miles 1959; Harmel et al. 2008; Tjallingii 2006). The possibility to feed aphids on an artificial diet and collect saliva has facilitated the identification of saliva proteins and their functions (Carolan et al. 2009; Cherqui and Tjallingii 2000; Harmel et al. 2008; Nicholson et al. 2012). Initially, saliva collections were found to exhibit enzymatic activities reflecting the presence of different types of enzymes, such as oxidoreductases and hydrolases (Leszczynski and Dixon 1990; Ma et al. 1990; Miles and Oertli 1993). However, the availability of advanced proteomics tools as well as aphid genome and transcriptome sequences now allows direct identification of proteins in aphid saliva.
One method of saliva collection employs an artificial diet system described by Cherqui and Tjallingii (2000). In this artificial diet system, aphids feed from a diet contained between layers of parafilm and the saliva collected can be distinguished as two fractions: soluble saliva (fraction contained in the fluid diets) and solid saliva (fraction remaining attached to the lower parafilm layer through which the aphids feed). Saliva collection methods in combination with proteomics have been instrumental in the identification of saliva proteins from several aphid species (Carolan et al. 2009; Harmel et al. 2008; Nicholson et al. 2012). These studies revealed that some of the predominant saliva proteins have predicted enzymatic activities (i.e., GMC oxidoreductases, glucose dehydrogenases, and proteases) and identified a number of proteins of unknown predicted function. The presence of a range of enzymes potentially reflects the need for aphids to detoxify plant defense components in order to successfully feed on their hosts (Harmel et al. 2008, Nicholson et al. 2012).

Surprisingly, approximately 30 and $50 \%$ of the proteins identified in saliva from $M$. persicae and $D$. noxia, respectively, did not contain a signal peptide sequence. This could indicate that some proteins are delivered into saliva via nonsecretory pathways. However, to rule out the possibility that they are contaminants, more biological replications of saliva proteomics experiments are needed to increase confidence that these proteins are, indeed, delivered into saliva.

There appears to be only limited overlap between the secreted saliva proteins identified for the different aphid species (Table 1). This lack of overlap could reflect a requirement for different sets of effectors to manipulate distinct hosts. Indeed, significant variation has been observed in the protein profiles of saliva collected from different aphid species and even biotypes (Cooper et al. 2011; Nicholson et al. 2012). In addition, only limited sequence information was available for A. pisum,

Table 1. Overview of Myzus persicae, Acyrthosiphon pisum, and Diuraphis noxia saliva proteins that contain a signal peptide sequence identified by proteomics using aphid saliva collections ${ }^{\mathrm{a}}$

\begin{tabular}{|c|c|c|c|c|c|c|}
\hline \multicolumn{3}{|c|}{ GB ID } & \multirow[b]{2}{*}{ M. persicae } & \multirow[b]{2}{*}{ A. pisum } & \multirow[b]{2}{*}{ D. noxia } & \multirow[b]{2}{*}{ Predicted function } \\
\hline A. pisum & M. persicae & Other & & & & \\
\hline XP_001943898 & EC387934 & $\ldots$ & $\mathrm{X}$ & $\mathrm{X}$ & $\ldots$ & Unknown \\
\hline NP_001155747 & EE572100 & $\ldots$ & $\mathrm{X}$ & $\mathrm{X}$ & $\ldots$ & Unknown \\
\hline NP_001155659 & EE264598 & $\ldots$ & $X$ & $\mathrm{X}$ & $\ldots$ & Unknown \\
\hline XP_001943703 & EE264560 & $\ldots$ & $\mathrm{X}$ & $\ldots$ & $\ldots$ & Unknown \\
\hline XP_001950631 & EE263445 & $\ldots$ & $\mathrm{X}$ & $\ldots$ & $\ldots$ & Unknown \\
\hline XP_001949532 & EE571076 & $\ldots$ & $\mathrm{X}$ & $\ldots$ & $\mathrm{X}$ & GMC oxidoreductase \\
\hline BĀH71891 & DW013464 & $\ldots$ & $\mathrm{X}$ & $\ldots$ & $\ldots$ & Unknown \\
\hline XP_001948358 & EC389283 & $\ldots$ & $\mathrm{X}$ & $\ldots$ & $\ldots$ & Unknown \\
\hline BAH71375 & EC389929 & $\ldots$ & $\mathrm{X}$ & $\ldots$ & $\ldots$ & Unknown \\
\hline NP_001155386 & DW011294 & $\ldots$ & $X$ & $\ldots$ & $\ldots$ & Unknown \\
\hline XP_003246887 & EE571055 & $\ldots$ & $\mathrm{X}$ & $\ldots$ & $\ldots$ & $\alpha$-Amylase \\
\hline NP_001233031 & DW010534 & $\ldots$ & $\mathrm{X}$ & $\ldots$ & $\mathrm{X}$ & Alcohol dehydrogenase \\
\hline XP_001946945 & $\ldots$ & $\ldots$ & $\ldots$ & $\mathrm{X}$ & $\ldots$ & Glucose dehydrogenase \\
\hline NP_001129384 & $\ldots$ & $\ldots$ & $\ldots$ & $\mathrm{X}$ & $\ldots$ & Angiotensin converting enzyme \\
\hline XP_001944764 & $\ldots$ & $\ldots$ & $\ldots$ & $\mathrm{X}$ & $\mathrm{X}$ & $\mathrm{m} 1$ Zinc metalloprotease \\
\hline \multirow[t]{2}{*}{ XP001943395 } & $\ldots$ & $\ldots$ & $\ldots$ & $\ldots$ & $\mathrm{X}$ & Glucose dehydrogenase \\
\hline & $\ldots$ & EAT34746 & $\ldots$ & $\ldots$ & $\mathrm{X}$ & Glucose dehydrogenase \\
\hline XP001946945 & $\ldots$ & $\ldots$ & $\ldots$ & $\ldots$ & $\mathrm{X}$ & Glucose dehydrogenase \\
\hline ХР001949219 & $\ldots$ & $\ldots$ & $\ldots$ & $\ldots$ & $\mathrm{X}$ & Apolipophorin \\
\hline \multirow[t]{3}{*}{ XP001947177 } & $\ldots$ & $\ldots$ & $\ldots$ & $\ldots$ & $\mathrm{X}$ & Chitinase \\
\hline & $\ldots$ & EFA00141 & $\ldots$ & $\ldots$ & $\mathrm{X}$ & Stretchin-myosin light chain kinase \\
\hline & $\ldots$ & EEB14435 & $\ldots$ & $\ldots$ & $\mathrm{X}$ & Cytochrome P450 \\
\hline XP001950264 & $\ldots$ & $\ldots$ & $\ldots$ & $\ldots$ & $\mathrm{X}$ & Trehalase \\
\hline \multirow[t]{2}{*}{ XP_001952612 } & $\ldots$ & $\ldots$ & $\ldots$ & $\ldots$ & $\mathrm{X}$ & Calreticulin-like isoform 1 \\
\hline & $\ldots$ & XP001870012 & $\ldots$ & $\ldots$ & $\mathrm{X}$ & Ficolin-3 \\
\hline \multirow[t]{2}{*}{ ХР001943071 } & $\ldots$ & $\ldots$ & $\ldots$ & $\ldots$ & $\mathrm{X}$ & $\begin{array}{l}\text { Acyl-coenzyme A:6-aminopenicillanic-acid- } \\
\text { acyltransferase }\end{array}$ \\
\hline & $\ldots$ & EFN89935 & $\ldots$ & $\ldots$ & $\mathrm{X}$ & Osiris 7 \\
\hline
\end{tabular}

${ }^{\text {a }}$ M. persicae proteins were identified by Harmel and associates (2008), A. pisum proteins by Carolan and associates (2009), and D. noxia proteins by Nicholson and associates (2012). 
$M$. persicae, and D. noxia at the time of these studies, which likely resulted in only a proportion of all saliva proteins being identified. With additional aphid genomes and transcriptomes being sequenced, proteomics-based identification of aphid salivary proteins is expected to improve. However, several limitations of using aphid saliva collections for effector identification are that i) proteins could be produced in amounts that are too low for detection by a mass spectrometer, ii) proteins may not be stable enough under feeding conditions to be present at detectable levels at the time of sample analyses, and iii) genes encoding the proteins may not be expressed when aphids are fed on artificial diets if plant cues are required to trigger their expression. Therefore, complementary approaches using transcriptome sequencing and proteomics of samples generated from dissected salivary glands are needed to gain further insight into the candidate effector repertoires of aphids. For example, Mutti and associates (2008) sequenced salivary gland cDNA libraries and identified the highly abundant $A$. pisum salivary protein $\mathrm{C} 002$. This aphid saliva protein plays an important role in feeding of A. pisum on host fava bean, because aphids with reduced $\mathrm{COO2}$ expression upon gene silencing spent very little time in contact with phloem sap in sieve elements (Mutti et al. 2006, 2008). The protein C002 contains an N-terminal secretion signal and is injected into the host plant during aphid feeding, as confirmed by $\mathrm{C} 002$-specific antibodies. Moreover, both the $\mathrm{C} 002$ protein and its corresponding transcript were localized in the principal salivary glands of the pea aphid (Mutti et al. 2008). Homologous C002 sequences have been found only in aphids, including Toxoptera citricida (brown citrus aphid), A. gossypii (the cotton aphid), M. persicae, and Schizaphis graminum (the greenbug). More recently, Bos and associates (2010) showed that overexpression in Nicotiana benthamiana of M. persicae C002 (MpC002) enhanced aphid fecundity, suggesting that this protein may promote aphid infestation (Bos et al. 2010).

The most extensive study to date to catalog aphid candidate effectors was reported by Carolan and associates (2011), where a dual transcriptomic-proteomic approach was applied on cDNA and proteins from dissected $A$. pisum salivary glands. In this multi-disciplinary study, expressed sequence tags (EST) from two salivary gland cDNA libraries were analyzed in order to find significantly over-represented transcripts. Then mass spectrometry on proteins isolated from both one- and two-dimensional separations of salivary gland homogenates was performed. Approximately $40 \%$ of predicted secreted salivary gland proteins identified using this approach did not have a predicted function based on similarity searches, or were only found in aphids but not in other insect species or organisms. Remarkably, several of the proteins identified in the predicted salivary secretome of $A$. pisum point to potential parallels between infestation and infection strategies of nematodes and aphids. In the predicted effector repertoires of both $A$. pisum and Meloidogyne incognita, proteins were identified with similarity to metalloproteases, disulfide isomerases, calreticulins, ARMET proteins, glutathione peroxidases, and CLIP-domain serine proteases (Carolan et al. 2011). These similarities may reflect that these distant groups of plant parasites have evolved similar strategies to combat plant defense or promote susceptibility.

Another multi-disciplinary approach used for the identification of aphid candidate effectors, in this case from the broadhost-range aphid Myzus persicae, was based on combining bioinformatics and functional assays to link sequence to phenotype (Bos et al. 2010). The application of this approach to publicly available salivary gland EST data sets identified $46 \mathrm{M}$. persicae predicted secreted proteins. Using a range of functional assays that were based on features of plant pathogen effectors, three aphid candidate effectors (Mp10, Mp42, and MpC002) were identified that affected aphid virulence. In addition, candidate aphid effector Mp10 was found to induce chlorosis upon overexpression in $N$. benthamiana, and suppressed the oxidative burst triggered by flg22 but not chitin (Bos et al. 2010). These activities of Mp10 resemble features of well-known pathogen effectors (Cunnac et al. 2009), indicating that functional genomics tools are effective in identifying candidate aphid effectors.

\section{Linking salivary proteins with effector activities.}

With the increasing number of salivary proteomics and transcriptomics studies, each generating lists of candidate effectors, the next essential step is to develop and apply appropriate functional assays to interrogate their functions. This will require the development of tools in a range of host plant species, including monocot and dicot species.

Because there are currently no approaches available for the genetic transformation of aphids, alternative methods will have to be used to characterize aphid candidate effectors and their functions. One tool that has been developed to study gene function in aphids is RNA interference (RNAi). This approach relies on the delivery of double-stranded (ds)RNA into aphids which, in turn, leads to silencing of the targeted gene. Initial reports of aphid gene silencing were based on microinjection of RNAi directly into the aphid body (Mutti et al. 2006). Although this approach has proven to be very useful, it involves injection of aphids, which can lead to injury and mortality, especially when using small aphid species. Another delivery method is feeding of aphids on an artificial diet that contains synthesized dsRNA. This method has been used successfully for silencing of several genes in the aphid species A. pisum. More recently, Pitino and associates (2011) described an approach to silence aphid genes in a more natural environment by expressing dsRNA inside plant cells. Plant-mediated RNAi can be applied to any plant species that can be either agroinfiltrated or genetically transformed and, thus, promises to be a useful tool to study aphid gene function during the interaction of aphids with a variety of crop or model plants.

Other functional assays utilize the overexpression of aphid proteins in planta to study their function. For example, the development of a leaf disc-based assay to determine whether overexpression of aphid candidate effectors alters aphid virulence allowed the screening of 46 different candidates (Bos et al. 2010) and revealed that several aphid candidate effectors from the aphid species $M$. persicae can alter aphid virulence. This assay can be easily adapted for use on whole plants by restricting aphids to agroinfiltrated leaf areas using cages. In this case, the assay will be more time consuming but may reveal activities that require intact plants. One requirement for such effector activity screens is that the host plant can be agroinfiltrated to express aphid candidate effectors. Thus, assays will have to be adapted and optimized for the relevant host plant species.

Another assay commonly used to test for effector activity in planta is suppression of PTI. Several plant pathogen effectors can suppress PTI triggered by a variety of MAMPs, including fungal chitin, bacterial flg22, and oomycete INF1 (Bos et al. 2006; de Jonge et al. 2010; Shan et al. 2008; Xiang et al. 2008). Although the role of PTI in plant-aphid interactions remains to be elucidated, screening aphid effector candidates for such activities may reveal insights in the plant signaling pathways affected by these proteins. As described above, the Mp10 candidate effector from $M$. persicae can suppress PTI triggered specifically by flg22. Further research is now ongoing to investigate whether this PTI suppression reflects a genuine effector activity upon recognition of an unknown MAMP-like molecule from aphids.

One limitation of all functional assays that aim to unveil effector activity toward successful aphid infestation is a lack of 
information regarding effector site of action. Because aphids can inject effectors directly into the host apoplast and cytoplasm, these proteins may not require specific translocation signals. This is in stark contrast to other organisms such as the oomycetes, where identification and verification of RXLR and LFLAK translocation signals allow reliable prediction of intracellular functions (Baxter et al. 2010; Haas et al. 2009; Schornack et al. 2010). In the absence of distinct effector identifiers, other general features are often considered important. These include the presence of a relatively large number of cysteines, a feature that may ensure levels of stability that are required for a hostile extracellular environment. Alternatively, predicting the activities of effector domains, if available, can help deduce which host compartment is targeted. In addition, as described above, aphids secrete saliva into different cell types, including into the phloem. It is possible that certain sets of effectors exhibit cell-type-specific activities, which may not necessarily be detected using 35S-based expression vectors. For example, certain aphid effectors may be specifically delivered and acting within the host phloem (Fig. 1). Although 35Sbased expression vectors allow expression in the phloem, expression will also occur in other host cell types and, thus, may affect detectable effector activities (Yang and Christou 1990). To test whether effectors are specifically active in the phloem, a phloem-specific promoter such as the AtSUC2 promoter may be required (Imlau et al. 1999). Furthermore, in addition to identifying aphid candidate effector activities, it is essential to investigate the cellular biology underlying both compatible and incompatible plant-aphid interactions.

\section{Outlook.}

The recent identification of predicted secreted salivary gland proteins that potentially function as effectors inside host plants indicated that there are parallels between the molecular mechanisms underlying plant-pathogen and plant-aphid interactions. This opens up new, exciting avenues to explore the extent of these parallels and determine, for example, how defenses such as PTI and ETI are important in plant-aphid interactions, and whether aphids and plant pathogens have evolved strategies to target similar plant proteins to render plants susceptible to infection and infestation. Herein, questions of interest include the following. What are the host targets of aphid effectors and how are they or their activities modified? Is there any overlap in the host targeting strategies of plant pathogens and aphids? What is the role of aphid effectors in determining aphid host range? A better understanding of the cell biology of plantaphid interactions in addressing these questions is essential.

With the number of aphid candidate effector identification studies increasing for a range of aphid species and biotypes, other questions arise. What is the extent of variation between their effector repertoires? What is the biological relevance of such variation? Current data already suggest that candidate effector repertoires of different aphid species and even biotypes are variable. This could reflect adaptation of different aphid species or biotypes to different hosts or genotypes. Thus, it will be interesting to investigate how aphid effector repertoires affect aphid host range and gene-for-gene interactions.

Also, additional aphid genomes and transcriptomes are currently being sequenced. The availability of such information will allow large-scale comparative analyses of aphid candidate effector repertoires and provide further insight into the evolution of plant-aphid interactions.

\section{ACKNOWLEDGMENTS}

We thank E. Huitema, P. Birch, and the anonymous reviewers for their useful comments on this manuscript. J. I. B. Bos is supported by the Royal
Society of Edinburgh and Marie Curie COFUND, and her lab is supported by the Biotechnology and Biological Sciences Research Council and the James Hutton Institute.

\section{LITERATURE CITED}

Adams, J. B., and Drew, M. E. 1965. A cellulose-hydrolyzing factor in aphid saliva. Can. J. Zool. 43:489-496.

Adams, J. B., and McAllan, J. W. 1956. pectinase in the saliva of Myzus persicae (SULZ.) (Homoptera: Aphididae). Can. J. Zool. 34:541-543.

Baxter, L., Tripathy, S., Ishaque, N., Boot, N., Cabral, A., Kemen, E., Thines, M., Ah-Fong, A., Anderson, R., Badejoko, W., Bittner-Eddy, P., Boore, J. L., Chibucos, M. C., Coates, M., Dehal, P., Delehaunty, K., Dong, S., Downton, P., Dumas, B., Fabro, G., Fronick, C., Fuerstenberg, S. I., Fulton, L., Gaulin, E., Govers, F., Hughes, L., Humphray, S., Jiang, R. H. Y., Judelson, H., Kamoun, S., Kyung, K., Meijer, H., Minx, P., Morris, P., Nelson, J., Phuntumart, V., Qutob, D., Rehmany, A., Rougon-Cardoso, A., Ryden, P., Torto-Alalibo, T., Studholme, D., Wang, Y., Win, J., Wood, J., Clifton, S. W., Rogers, J., Van den Ackerveken, G., Jones, J. D. G., McDowell, J. M., Beynon, J., and Tyler, B. M. 2010. Signatures of adaptation to obligate biotrophy in the $\mathrm{Hy}$ aloperonospora arabidopsidis Genome. Science 330:1549-1551.

Bellafiore, S., Shen, Z., Rosso, M.-N., Abad, P., Shih, P., and Briggs, S. P. 2008. Direct identification of the Meloidogyne incognita secretome reveals proteins with host cell reprogramming potential. PLoS Pathog. 4:e1000192. Published online.

Blackman, L. and Eastop, V. F. 2000. Aphids on the world crops. Wiley \& Sons, Chichester, U.K.

Bos, J. I. B., Kanneganti, T.-D., Young, C., Cakir, C., Huitema, E., Win, J., Armstrong, M. R., Birch, P. R. J., and Kamoun, S. 2006. The C-terminal half of Phytophthora infestans RXLR effector AVR3a is sufficient to trigger R3a-mediated hypersensitivity and suppress INF1-induced cell death in Nicotiana benthamiana. Plant J. 48:165-176.

Bos, J. I. B., Prince, D., Pitino, M., Maffei, M. E., Win, J., and Hogenhout, S. A. 2010. A functional genomics approach identifies candidate effectors from the aphid species Myzus persicae (green peach aphid). PLoS Genet. 6:e1001216. Published online.

Bozkurt, T. O., Schornack, S., Banfield, M. J., and Kamoun, S. 2012. Oomycetes, effectors, and all that jazz. Curr. Opin. Plant Biol. 15:483-492.

Carolan, J. C., Fitzroy, C. I. J., Ashton, P. D., Douglas, A. E., and Wilkinson, T. L. 2009. The secreted salivary proteome of the pea aphid Acyrthosiphon pisum characterised by mass spectrometry. Proteomics 9:2457-2467.

Carolan, J. C., Caragea, D., Reardon, K. T., Mutti, N. S., Dittmer, N., Pappan, K., Cui, F., Castaneto, M., Poulain, J., Dossat, C., Tagu, D., Reese, J. C., Reeck, G. R., Wilkinson, T. L., and Edwards, O. R. 2011. Predicted effector molecules in the salivary secretome of the pea aphid (Acyrthosiphon pisum): A dual transcriptomic/proteomic approach. J. Proteome Res. 10:1505-1518.

Casteel, C. L., Walling, L. L., and Paine, T. D. 2006. Behavior and biology of the tomato psyllid, Bactericerca cockerelli, in response to the $M i-1.2$ gene. Entomol. Exp. Appl. 121:67-72.

Cherqui, A., and Tjallingii, W. F. 2000. Salivary proteins of aphids, a pilot study on identification, separation and immunolocalisation. J. Insect Physiol. 46:1177-1186.

Cooper, W. R., Dillwith, J. W., and Puterka, G. J. 2011. Comparisons of salivary proteins from five aphid (Hemiptera: Aphididae) species. Environ. Entomol. 40:151-156.

Cunnac, S., Lindeberg, M., and Collmer, A. 2009. Pseudomonas syringae type III secretion system effectors: Repertoires in search of functions. Curr. Opin. Microbiol. 12:53-60.

de Jonge, R., van Esse, H. P., Kombrink, A., Shinya, T., Desaki, Y., Bours, R., van der Krol, S., Shibuya, N., Joosten, M. H. A. J., and Thomma, B. P. H. J. 2010. Conserved fungal LysM effector Ecp6 prevents chitintriggered immunity in plants. Science 329:953-955.

de Vos, M., and Jander, G. 2009. Myzus persicae (green peach aphid) salivary components induce defence responses in Arabidopsis thaliana. Plant Cell Environ. 32:1548-1560.

Deslandes, L., and S. Rivas, 2012. Catch me if you can: Bacterial effectors and plant targets. Trends Plant Sci. 17:644-655.

Dogimont, C., Bendahmane, A., Chovelon, V., and Boissot, N. 2010. Host plant resistance to aphids in cultivated crops: Genetic and molecular bases, and interactions with aphid populations. C. R. Biol. 333:566-573.

Girousse, C., Moulia, B., Silk, W., and Bonnemain, J.-L. 2005. Aphid infestation causes different changes in carbon and nitrogen allocation in alfalfa stems as well as different inhibitions of longitudinal and radial expansion. Plant Physiol. 137:1474-1484.

Guttman, D. S., Vinatzer, B. A., Sarkar, S. F., Ranall, M. V., Kettler, G., and Greenberg, J. T. 2002. A functional screen for the type III (Hrp) se- 
cretome of the plant pathogen Pseudomonas syringae. Science 295:1722-1726.

Haas, B. J., Kamoun, S., Zody, M. C., Jiang, R. H. Y., Handsaker, R. E., Cano, L. M., Grabherr, M., Kodira, C. D., Raffaele, S., Torto-Alalibo, T., Bozkurt, T. O., Ah-Fong, A. M. V., Alvarado, L., Anderson, V. L., Armstrong, M. R., Avrova, A., Baxter, L., Beynon, J., Boevink, P. C. Bollmann, S. R., Bos, J. I. B., Bulone, V., Cai, G., Cakir, C., Carrington, J. C., Chawner, M., Conti, L., Costanzo, S., Ewan, R., Fahlgren, N., Fischbach, M. A., Fugelstad, J., Gilroy, E. M., Gnerre, S., Green, P. J., Grenville-Briggs, L. J., Griffith, J., Grunwald, N. J., Horn, K., Horner, N. R., Hu, C. H., Huitema, E., Jeong, D. H., Jones, A. M. E., Jones, J. D. G., Jones, R. W., Karlsson, E. K., Kunjeti, S. G., Lamour, K., Liu, Z., Ma, L., MacLean, D., Chibucos, M. C., McDonald, H., McWalters, J., Meijer, H. J. G., Morgan, W., Morris, P. F., Munro, C. A., O’Neill, K., Ospina-Giraldo, M., Pinzon, A., Pritchard, L., Ramsahoye, B., Ren, Q., Restrepo, S., Roy, S., Sadanandom, A., Savidor, A., Schornack, S., Schwartz, D. C., Schumann, U. D., Schwessinger, B., Seyer, L., Sharpe, T., Silvar, C., Song, J., Studholme, D. J., Sykes, S., Thines, M., van de Vondervoort, P. J. I., Phuntumart, V., Wawra, S., Weide, R., Win, J., Young, C., Zhou, S., Fry, W., Meyers, B. C., van West, P., Ristaino, J., Govers, F., Birch, P. R. J., Whisson, S. C., Judelson, H. S., and Nusbaum, C. 2009. Genome sequence and analysis of the Irish potato famine pathogen Phytophthora infestans. Nature 461:393-398.

Harmel, N., Létocart, E., Cherqui, A., Giordanengo, P., Mazzucchelli, G., Guillonneau, F., De Pauw, E., Haubruge, E., and Francis, F. 2008. Identification of aphid salivary proteins: A proteomic investigation of Myzus persicae. Insect Mol. Biol.17:165-174.

Hewer, A., Becker, A., and van Bel, A. J. E. 2011. An aphid's Odysseythe cortical quest for the vascular bundle. J. Exp. Biol. 214:3868-3879.

Hewezi, T., and Baum, T. 2013.Manipulation of plant cells by cyst and root-knot nematode effectors. Mol. Plant-Microbe Interact. 26:9-16.

Hill, C. B., Crull, L., Herman, T. K., Voegtlin, D. J., and Hartman, G. L. 2010. A new soybean aphid (Hemiptera: Aphididae) biotype identified. J. Econ. Entomol. 103:509-515

Hogenhout, S. A., and Bos, J. I. 2011. Effector proteins that modulate plant-insect interactions. Curr. Opin. Plant Biol. 14:422-428.

Imlau, A., Truernit, E., and Sauer, N. 1999. Cell-to-cell and long-distance trafficking of the green fluorescent protein in the phloem and symplastic unloading of the protein into sink tissues. Plant Cell 11:309-322.

International Aphid Genomics Consortium. 2010. Genome sequence of the pea aphid Acyrthosiphon pisum. PLoS Biol. 8:e1000313. Published online.

Joly, D. L., Feau, N., Tanguay, P., and Hamelin, R. C. 2010. Comparative analysis of secreted protein evolution using expressed sequence tags from four poplar leaf rusts (Melampsora spp.). BMC Genomics 11:422.

Jones, J. D. G., and Dangl, J. L. 2006. The plant immune system. Nature 444:323-329.

Kim, K.-S., Bellendir, S., Hudson, K. A., Hill, C. B., Hartman, H. D. L., Hudson, M. E., and Diers, B. W. 2010. Fine mapping the soybean aphid resistance gene Rag1 in soybean. Theor. Appl. Genet. 120:1063-1071.

Klingler, J., Creasy, R., Gao, L., Nair, R. M., Calix, A.S., Jacob, H. S., Edwards, O. R., and Singh, K. B. 2005. Aphid resistance in Medicago truncatula involves antixenosis and phloem-specific, inducible antibiosis, and maps to a single locus flanked by NBS-LRR resistance gene analogs. Plant Physiol. 137:1445-1455.

Klingler, J. P., Nair, R. M., Edwards, O. R., and Singh, K. B. 2009. A single gene, AIN, in Medicago truncatula mediates a hypersensitive response to both bluegreen aphid and pea aphid, but confers resistance only to bluegreen aphid. J. Exp. Bot. 60:4115-4127.

Knoblauch, M., Peters, W. S., Ehlers, K., and Van Bel, A. J. E. 2001. Reversible calcium-regulated stopcocks in legume sieve tubes. Plant Cell 13:1221-1230.

Leszczynski, B., and Dixon, A. F. G. 1990. Resistance of cereals to aphids: Interaction between hydroxamic acids and the aphid Sitobion avenae (Homoptera: Aphididae). Ann. Appl. Biol. 117:21-30.

Ma, R., Reese, J. C., Black. W. C. IV, and Bramel-Cox, P. 1990. Detection of pectinesterase and polygalacturonase from salivary secretions of living greenbugs, Schizaphis graminum (Homoptera: Aphididae). J. Insect Physiol. 36: 507-512.

McLean, D. L., and Kinsey, M. G. 1968 Probing behavior of the pea aphid, Acyrthosiphon pisum. II. Comparisons of salivation and ingestion in host and non-host plant leaves. Ann. Entomol. Soc. Am. 61:730739

Miles, P. W. 1959. Secretion of two types of saliva by an aphid. Nature 183:756-756

Miles, P. W. 1965. Studies on the salivary physiology of plant-bugs: The salivary secretions of aphids. J. Insect Physiol. 11:1261-1268.
Miles, P. W., and Oertli, J. J. 1993. The significance of antioxidants in the aphid-plant interaction: The redox hypothesis. Entomol. Exp. Appl. 67:275-283.

Milligan, S. B., Bodeau, J., Yaghoobi, J., Kaloshian, I., Zabel, P., and Williamson, V. M. 1998. The root knot nematode resistance gene $M i$ from tomato is a member of the leucine zipper, nucleotide binding, leucine-rich repeat family of plant genes. Plant Cell 10:1307-1320.

Mutti, N. S., Park, Y., Reese, J. C., and Reeck, G. R. 2006. RNAi knockdown of a salivary transcript leading to lethality in the pea aphid, Acyrthosiphon pisum. J. Insect Sci. 6:1-7.

Mutti, N. S., Louis, J., Pappan, L. K., Pappan, K., Begum, K., Chen, M.S., Park, Y., Dittmer, N., Marshall, J., Reese, J. C., and Reeck, G. R. 2008. A protein from the salivary glands of the pea aphid, Acyrthosiphon pisum, is essential in feeding on a host plant. Proc. Natl. Acad. Sci. U.S.A. 105:9965-9969.

Nicholson, S. J., Hartson, S. D., and Puterka, G. J. 2012. Proteomic analysis of secreted saliva from Russian wheat aphid (Diuraphis noxia Kurd.) biotypes that differ in virulence to wheat. J. Proteomics 75:22522268

Nombela, G., Williamson, V. M., and Muñiz, M. 2003. The root-knot nematode resistance gene $\mathrm{Mi}-1.2$ of tomato is responsible for resistance against the whitefly Bemisia tabaci. Mol. Plant-Microbe Interact. 16:645-649.

Pitino, M., Coleman, A. D., Maffei, M. E., Ridout, C. J., and Hogenhout, S. A. 2011. Silencing of aphid genes by dsRNA feeding from plants. PLoS One 6:e25709. Published online.

Rafiqi, M., Ellis, J. G., Ludowici, V. A., Hardham, A. R., and Dodds, P. N. 2012. Challenges and progress towards understanding the role of effectors in plant-fungal interactions. Curr. Opin. Plant Biol. 15:477-482.

Ramsey, J. S., Wilson, A. C., de Vos, M., Sun, Q., Tamborindeguy, C., Winfield, A., Malloch, G., Smith, D. M., Fenton, B., Gray, S. M., et al. 2007. Genomic resources for Myzus persicae: EST sequencing, SNP identification, and microarray design. BMC Genomics 8:423.

Rossi, M., Goggin, F. L., Milligan, S. B., Kaloshian, I., Ullman, D. E., and Williamson, V. M. 1998. The nematode resistance gene $\mathrm{Mi}$ of tomato confers resistance against the potato aphid. Proc. Natl. Acad. Sci. U.S.A. 95:9750-9754.

Schornack, S., Van Damme, M., Bozkurt, T. O., Cano, L. M., Smoker, M., Thines, M., Gaulin, E., Kamoun, S., and Huitema, E. 2010. Ancient class of translocated oomycete effectors targets the host nucleus. Proc. Natl. Acad. Sci. U.S.A. 107:17421-17426.

Seah, S., Sivasithamparam, K., Karakousis, A., and Lagudah, E. S. 1998. Cloning and characterization of a family of disease resistance genes analogs from wheat and barley. Theor. Appl. Genet. 97:937-945.

Shan, L., He, P., Li, J., Heese, A., Peck, S. C., Nürnberger, T., Martin, G. B., and Sheen, J. 2008. Bacterial effectors target the common signaling partner BAK1 to disrupt multiple MAMP receptor-signaling complexes and impede plant immunity. Cell Host Microbe 4:17-27.

Tjallingii, W. F. 2006. Salivary secretions by aphids interacting with proteins of phloem wound responses. J. Exp. Bot. 57:739-745.

Tjallingii, W. F., and Esch, T.H. 1993. Fine structure of aphid stylet routes in plant tissues in correlation with EPG signals. Physiol. Entomol. 18:317-328.

van Emden, H. F., and Harrington, R. 2007. Aphids as Crop Pests. CABI International, Wallingford, U.K.

Wiktelius, S. 1982. Flight and settling behaviour of Rhopalosiphum Padi (L.) (Hemiptera: Aphididae). Bull. Entomol. Res. 72:157-163.

Will, T., Tjallingii, W. F., Thönnessen, A., and van Bel, A. J. E. 2007. Molecular sabotage of plant defense by aphid saliva. Proc. Natl. Acad. Sci. U.S.A. 104:10536-10541.

Will, T., Kornemann, S. R., Furch, A. C. U., Tjallingii, W. F., and Van Bel, A. J. E. 2009. Aphid watery saliva counteracts sieve-tube occlusion: A universal phenomenon? J. Exp. Biol. 212:3305-3312.

Wilson, A. C. C., Sternberg, L. D. S. L., and Hurley, K. B. 2011. Aphids alter host-plant nitrogen isotope fractionation. Proc. Natl. Acad. Sci. U.S.A. 108:10220-10224.

Wroblewski, T., Piskurewicz, A., Tomczak, O., Ochoa, O., and Michelmore, R. W. 2007. Silencing of the major family of NBS-LRR-encoding genes in lettuce results in the loss of multiple resistance specificities. Plant J. 51:803-818.

Xiang, T., Zong, N., Zou, Y., Wu, Y., Zhang, J., Xing, W., Li, Y., Tang, X., Zhu, L., Chai, J., and Zhou, J. M. 2008. Pseudomonas syringae effector AvrPto blocks innate immunity by targeting receptor kinases. Curr. Biol. 18:74-80

Yang, N.-S., and Christou, P. 1990. Cell type specific expression of a CaMV 35S-GUS gene in transgenic soybean plants. Develop Genet 11:289-293. 